\section{EMBRYARIDDLE \\ Aeronautical University}

SCHOLARLY COMMONS
International Journal of Aviation, Aeronautics, and Aerospace

\title{
Small Unmanned Aircraft Systems Acoustic Analysis for Noninvasive Marine Mammal Response: An Exploratory Field Study
}

\author{
David Thirtyacre \\ Embry-Riddle Aeronautical University, thirtyad@erau.edu \\ Gennifer Brookshire \\ genniferbrookshire@gmail.com \\ Sarah Callan \\ secall04@gmail.com \\ Brittany Arvizu \\ bkarvizu@gmail.com \\ Patrick Sherman \\ Embry-Riddle Aeronautical University, shermanp@erau.edu
}

Follow this and additional works at: https://commons.erau.edu/ijaaa

Part of the Aeronautical Vehicles Commons, Aquaculture and Fisheries Commons, Astrodynamics Commons, Aviation Safety and Security Commons, Other Animal Sciences Commons, Propulsion and Power Commons, and the Terrestrial and Aquatic Ecology Commons

\section{Scholarly Commons Citation}

Thirtyacre, D., Brookshire, G., Callan, S., Arvizu, B., \& Sherman, P. (2021). Small Unmanned Aircraft Systems Acoustic Analysis for Noninvasive Marine Mammal Response: An Exploratory Field Study. International Journal of Aviation, Aeronautics, and Aerospace, 8(2). https://doi.org/10.15394/ijaaa.2021.1584

This Article is brought to you for free and open access by the Journals at Scholarly Commons. It has been accepted for inclusion in International Journal of Aviation, Aeronautics, and Aerospace by an authorized administrator of Scholarly Commons. For more information, please contact commons@erau.edu. 
The use of small Unmanned Aircraft Systems (sUAS) in wildlife monitoring (Fust \& Loos, 2019) and marine animal research (Aniceto et al., 2018; Adame et al., 2017; Douglas et al., 2017; Fiori et al., 2017; Goebel et al., 2010; Krause et al., 2017; Marine Mammal Commission, 2016; Seymour et al., 2017; Schofield et al., 2019; Sorrel et al., 2019) have been studied, along with costbenefits analyses (MMC, 2016; Raoult et al., 2020). Unmanned aircraft allow access to remote and rugged terrain, enable data collection at a lower cost than traditional aerial methods, and permit observation of species wary of human presence. They have been used to measure reproduction, body condition, and population counts of marine mammals, including pinnipeds. Pinnipeds (Pinnipedia) are comprised of three families; Phocidae (seals), Otariidae (sea lions), and Odobenidae (walruses).

The use of sUAS for entangled/stranded pinniped response efforts has been recommended (MMC, 2016), but not been consistently implemented; therefore, further research is warranted. Unmanned aircraft could be beneficial in pinniped response efforts by allowing the response team to monitor target individual(s) from a safe distance in hard-to-reach locations without disturbing the individual(s) or conspecifics at haul-out sites. Previous studies have shown that pinnipeds have a variety of reactions to the presence of sUAS in their immediate vicinity. Pinniped reactions may include; no response, looking in the direction of the aircraft, or fleeing into the water (Adame et al., 2017; Islam et al., 2017; McIntosh et al., 2018; MMC, 2016; Raoult et al., 2020; Smith et al., 2017). The sound pressure level (SPL) generated by the sUAS and the environment's ambient noise have not been uniformly reported during occurrences of pinniped sUAS reaction, but must be considered prior to aircraft employment.

The purpose of this research was to develop acoustic profiles of multiple sUAS, across a range of distance and altitude from the subject, to provide information to the marine mammal research community on the SPL of various sUAS. In addition, the results from this exploratory field study were used to create flight envelopes (altitude and distance) based on noise levels below the ambient noise floor. The study provides a reference point for potential noninvasive use of sUAS for pinniped and other wildlife applications. The specific research questions were:

1. To what extent does altitude and distance affect the SPL created by a stationary sUAS?

2. To what extent does aircraft type affect the SPL created by a stationary sUAS?

3. At what SPL below the ambient coastal ocean noise does a sUAS become inaudible?

The acoustic profiles were developed using both quantitative and qualitative measures. Quantitative measures included a Type 2 data logging microphone as 
well as a wide-spectrum microphone connected to an auditory spectrum analyzer. Qualitative measures took the form of subjective judgment by human participants, rendered on a six-point scale, to assess the perceived sound of the aircraft relative to the background noise of the environment.

This research was conducted in two phases. Phase- 1 occurred in a secluded rural environment selected for its relative absence of human generated noise, as well as a consistent, quiet background noise. The purpose of Phase-1 was to determine the acoustic characteristics of each aircraft in a controlled field environment. Phase- 2 occurred in a coastal environment typical of where pinnipeds are found, being a mix of sandy beaches and large boulders. The coastal environment ambient SPL was significantly higher than the rural environment.

During Phase-1, nine aircraft were tested. However, owing to a common airframe design among several platforms built by the same manufacturer with different sensor payloads, results were effectively obtained for a dozen aircraft. During Phase-2, the four aircrafts found to produce the lowest SPL disturbance during Phase-1 were subject to the additional testing.

This research aimed to provide information to the marine mammal community, specifically pinniped response efforts, on the SPL of various drones. The SPLs can be used as a resource when selecting a drone and defining a flight envelope (i.e., range and altitude away from the subject), that could prevent a disturbance or flee response while optimizing visual information. Even though this project was designed to monitor pinnipeds, the information gathered on the SPL of various drones and flight envelopes may be applicable to many wildlife research and response efforts.

\section{Materials and Methods \\ Limitations, Delimitations, and Assumptions}

There were several limitations to this exploratory field study. The limitations included access to test aircraft, research instrumentation, and test area intrusion by vehicles, aircraft, boats, and individuals. The test aircraft were a mix of University owned aircraft and personal aircraft. While this included many popular models, several aircraft were not available for testing. The research did not utilize multiple sound measurement devices to remove errors associated with instrumentation. Although the results were consistent, additional measurement devices were desired. During both Phase-1 and Phase-2, every attempt was made to eliminate human generated noise by suspending data collection while vehicles and individuals transited the area, however they may have influenced some of the results.

This study was delimited by the specific requirements for fieldwork. Specifically, the aircraft cost less than $\$ 3,000 \mathrm{USD}$, is portable by one person, capable of hand launch and recovery, support $4 \mathrm{k}$ video, and allows real-time 
identification of injured/entangled wildlife. While the Inspire-2 was at the limit of these parameters, it was included due to the large quantity of available sensor options and the common use of similar platforms in the field.

There were several assumptions in the study. Through earlier tests, the main aircraft noise was assumed to be below $6,000 \mathrm{~Hz}$. This is consistent with Feight (2014) which determined the majority of sound pressure came from motor noise and blade passing frequency and occurred in the $600-6,000 \mathrm{~Hz}$ range. Kloet et al.'s (2017) findings were similar in that the majority of the noise was generated in the $650-2,110 \mathrm{~Hz}$ range. Although harmonics were seen at higher frequencies, the intensity of those harmonics were significantly lower than the main disturbance above $6,000 \mathrm{~Hz}$. Since some species of pinnipeds are known for auditory response above the human limit of approximately $22,000 \mathrm{~Hz}$, it was assumed that the noise from the aircraft above 22,000 Hz was negligible.

Kloet et al. (2017) concluded that the noise levels varied slightly at different positions around the sUAS. The variation was not considered in this exploratory field study. Therefore, it was assumed that the sound pressure was the same regardless of aircraft orientation (i.e., the direction the aircraft was pointing compared to the measurement sensor). Also, it was assumed that the unique noise signature of a drone could be recognized by pinnipeds even though the aircraft noise was below the ambient background (Holt \& Schusterman, 2006). Finally, the aircraft parameters used during the test were assumed to be correct. While the position may vary, it was assumed that the telemetry indications on each aircraft's ground control station (GCS) were correct and that each aircraft was positioned correctly at each data collection point.

\section{Materials}

The materials included a Type 2 Sound Level Meter and accompanying computer software, an acoustic spectrum analyzer, various microphones, an anemometer, and test aircraft. The sound meter was a Reed 8080 data logging microphone calibrated for frequencies between $20-8,000 \mathrm{~Hz}$ with an accuracy of $\pm 1.4 \mathrm{~dB}$. This Type 2 microphone is commonly used for general fieldwork and studies (Malchaire, 2001). In accordance with microphones used in studies on marine mammal audiometry (Ruser et al., 2014) and SPL of sUAS for use in marine mammal studies (Palomino-González, et al., 2021) all SPL measurements were Aweighted (re $20 \mu \mathrm{Pa})$ using standard fast $(0.125 \mathrm{~s})$ exponential time-averaging per industrial environmental noise standards. Several microphones were tested for frequency response input to the spectrum analyzer. The microphone that exhibited the widest frequency response was selected and exhibited adequate response up to the spectrum analyzer limit of 22,000 Hz.

The aircraft tested included:

- Autel Evo

- DJI Inspire-2 
- DJI Mavic 2 Zoom (with aftermarket low noise propellers)

- DJI Mavic Pro (with aftermarket low noise propellers)

- DJI Phantom 4 Pro

- Parrot Anafi

- PowerVision PowerEgg X

- Skydio 2

- Yuneec Typhoon H

Note: Although not flown during this test, the Mavic 2 Pro and Mavic 2 Enterprise Dual are assumed to have similar acoustic characteristics to the Mavic 2 Zoom.

Aftermarket propellers, advertised to reduce noise, were used where available. The DJI Mavic 2 Zoom and Mavic Pro utilized Master Airscrew Stealth propellers. Field tests indicated that a reduction of 1.5-2.5 dBA was realized through use of the aftermarket propellers.

\section{Data Collection}

Data collection for Phase-1 took place in the U.S., near Eatonville, WA (N46.858, W122.358) in an area with sparse road and air traffic. The location proved ideal for data collection since the ambient noise did not vary more than \pm 2.0 $\mathrm{dBA}$ throughout the two-day collection period. During times of increased noise (e.g., aircraft overhead, wind) the test was suspended until the source of the noise departed the area and was no longer audible. The data collection for Phase-2 took place in the U.S., near Grayland, WA (N46.737, W124.077) on the Pacific Ocean. The only audible noise other than that created by waves was an occasional boat passing through the area. The tests were suspended until the boats passed.

Data was recorded with the Type 2 microphone and spectrum analyzer, and subjective ratings were made on a scale of $0-5$. The rating categories were:

$0=$ Cannot hear aircraft

$1=$ Cannot continuously hear aircraft

$2=$ Can continuously hear aircraft but level similar to background

$3=$ Can continuously hear aircraft just above background noise

$4=$ Can continuously hear aircraft as most prominent noise

$5=$ Can continuously hear aircraft, difficult to hear background noise

Phase-1: Acoustic Characteristics in a Controlled Field Environment. The objective of Phase-1 was to collect noise data from several aircraft to characterize each aircraft's signature at multiple positional locations (altitude and distance). The secondary objective was to determine if the independent variables (altitude and distance) could predict the dependent variable (SPL). The final objective was to narrow the number of aircraft for use in Phase-2.

Phase-2: Acoustic Characteristics in Coastal Environment. The objective of Phase-2 was to determine the extent of aircraft noise propagation in a coastal environment. The four aircraft with the lowest acoustic signature were flown in the 
coastal environment. The aircraft included the DJI Mavic Pro, DJI Mavic-2 Zoom, Parrot Anafi, and PowerEgg X. Each aircraft was flown and recorded at the same altitude and distance positions used during Phase-1.

\section{Results}

Phase-1: Aircraft Acoustic Characteristics in a Controlled Field Environment.

Each aircraft was tested at 35 different positions ranging from $10 \mathrm{~m}$ directly overhead to an altitude of $100 \mathrm{~m}$ and horizontal range from $0.0 \mathrm{~m}$ to $100 \mathrm{~m}$. The parameters for each collection position were determined through a pilot study based on the location and instrumentation available. In all cases, more than $20 \mathrm{SPL}$ measurements were recorded by the R8080 at each of the 35 data collection positions for each aircraft. The mean of each position for each aircraft was used to generate the acoustic envelope displayed in Figure 1. Although this is an unconventional use of the box plots, it illustrates the acoustic envelope of each aircraft over all 35 collection points. Each boxplot can be interpreted as the measured acoustic envelope for each aircraft (including outliers) at the tested parameters.

Figure 1

Boxplot of all Data Points Plotted by Aircraft

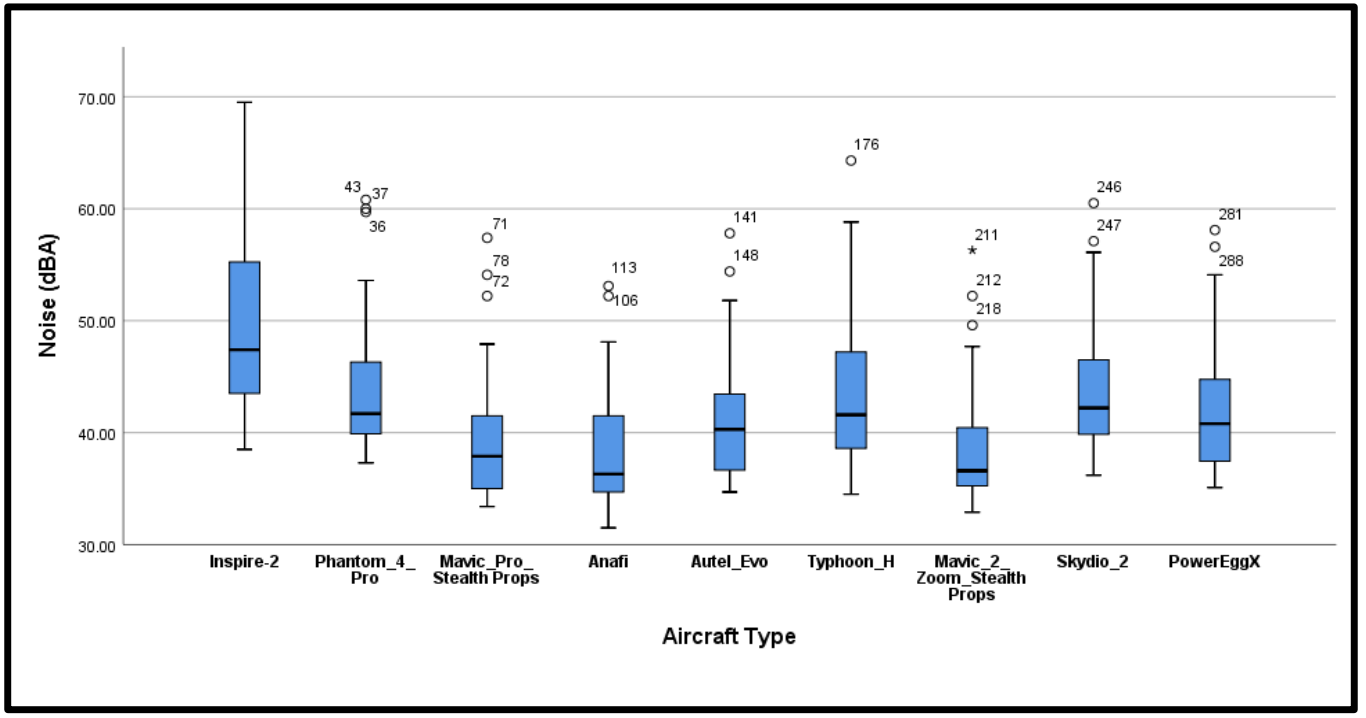

Graphs for each aircraft at each specific altitude and distance were generated to visualize the data. Figure 2 depicts the sound pressure levels at each altitude based on horizontal distance for the Yuneec Typhoon $\mathrm{H}$. 


\section{Figure 2}

Sound Pressure Level (dBA) Versus Distance (m) at Each Altitude (m) for the Typhoon $H$

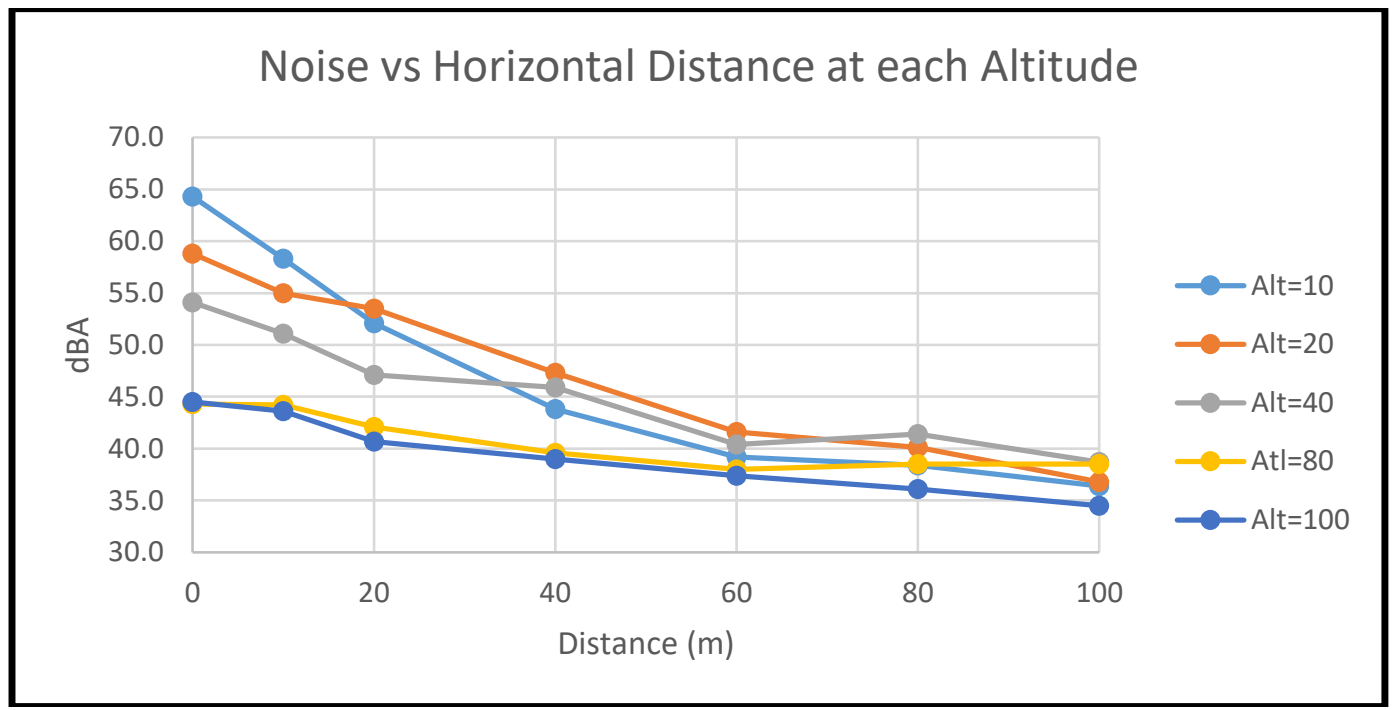

The spectrum analyzer was not a calibrated instrument, and therefore, not used for quantitative data collection. However, it proved to be an excellent tool to visualize the noise generated by the aircraft.

Figure 3

Spectrum Trace of Phantom 4 Pro at 20 m Altitude and $40 \mathrm{~m}$ Horizontal Distance

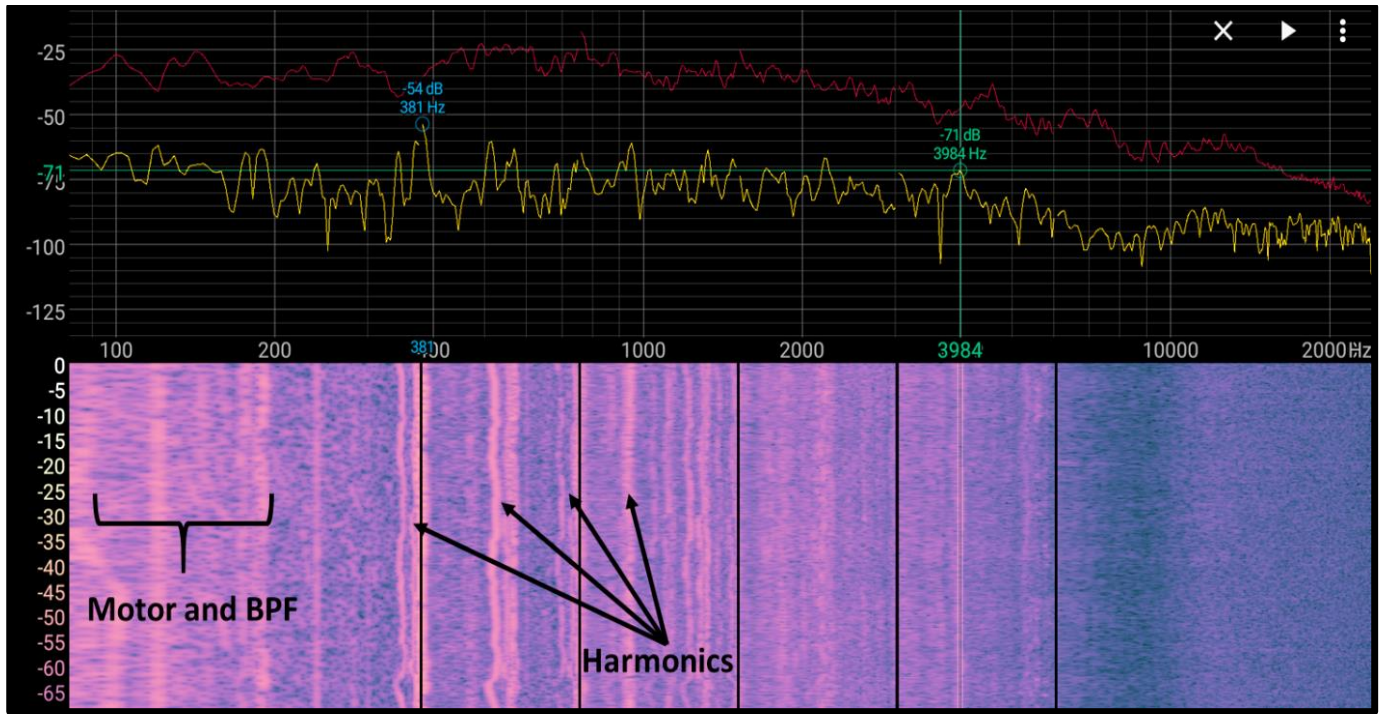


The waterfall history provided visual confirmation of the harmonics and intensity. Similar to Feight (2014), the majority of the noise was generated from the motor and blade passing frequency occurring in the $80-200 \mathrm{~Hz}$ area. The harmonics between $380-800 \mathrm{~Hz}$ were identified as the highest magnitude SPL for all aircraft as seen in Figure 3. For the Phantom 4 Pro, the highest sound pressure occurred at $386 \mathrm{~Hz}$. The harmonic intensity level can be seen fading in the 2000$6000 \mathrm{~Hz}$ area.

The aircraft with lower noise levels, as measured by the R8080, also produced the weakest harmonics that were not detectable above approximately $1500 \mathrm{~Hz}$ as seen with the Mavic 2 Zoom in Figure 4. For comparison purposes, the data in Figure 4 were measured at the same altitude and distance as Figure 3, illustrating the difference in aircraft SPL footprints. The maximum noise level from the Phantom 4 Pro (Figure 3) was $43.6 \mathrm{dBA}$ while the Mavic 2 Zoom was $37.6 \mathrm{dBA}$ at the same distance and altitude. As the aircraft distance increased, the sound pressure decreased as expected. Some of the aircraft became only intermittently audible to the human ear at $100 \mathrm{~m}$ and were only noticeable because of the unique sound of the aircraft. At those distances, the measured sound pressure was not above the noise floor and the waterfall history confirmed only small traces of aircraft generated sound. This was an important finding and directly applicable to the Phase- 2 testing. Figure 5 illustrates this result for the Mavic 2 Zoom at $20 \mathrm{~m}$ altitude and $100 \mathrm{~m}$ horizontal distance.

\section{Figure 4}

Spectrum Trace of Mavic 2 Zoom at 20 m Altitude and $40 \mathrm{~m}$ Horizontal Distance

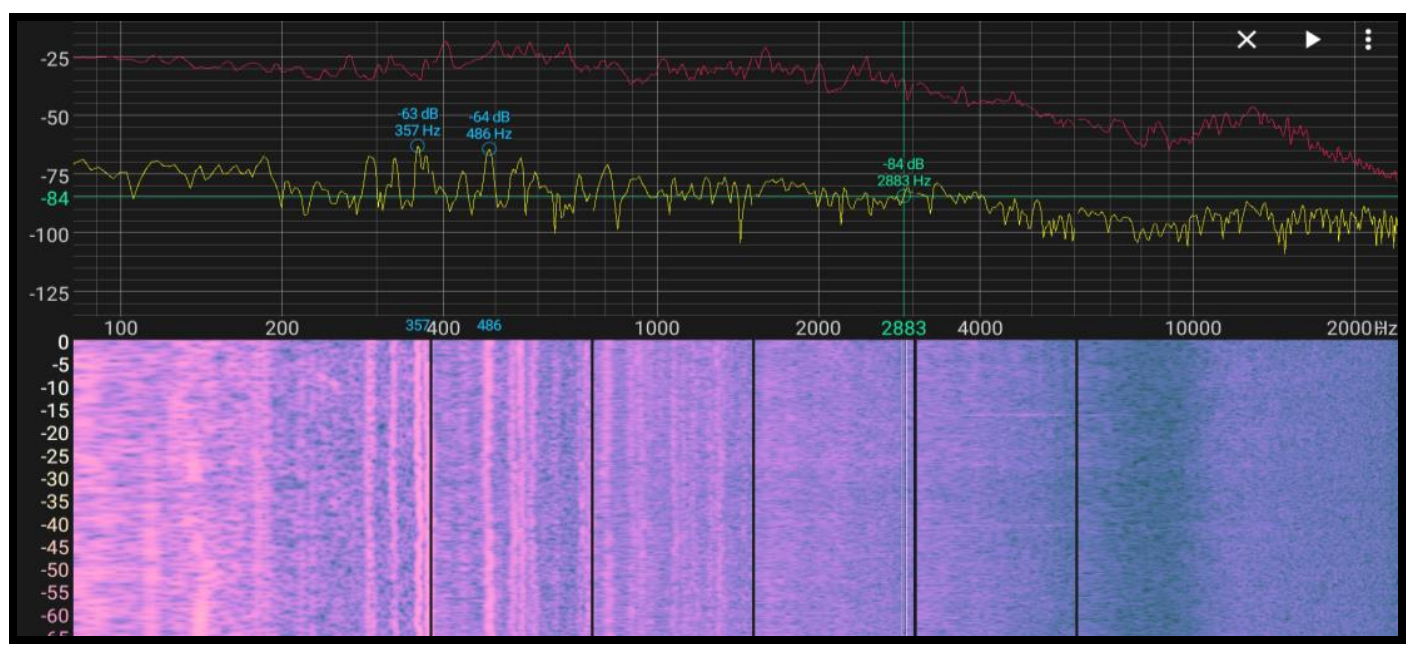




\section{Figure 5}

Spectrum Trace of Mavic 2 Zoom at $20 \mathrm{~m}$ Altitude and $100 \mathrm{~m}$ Horizontal Distance

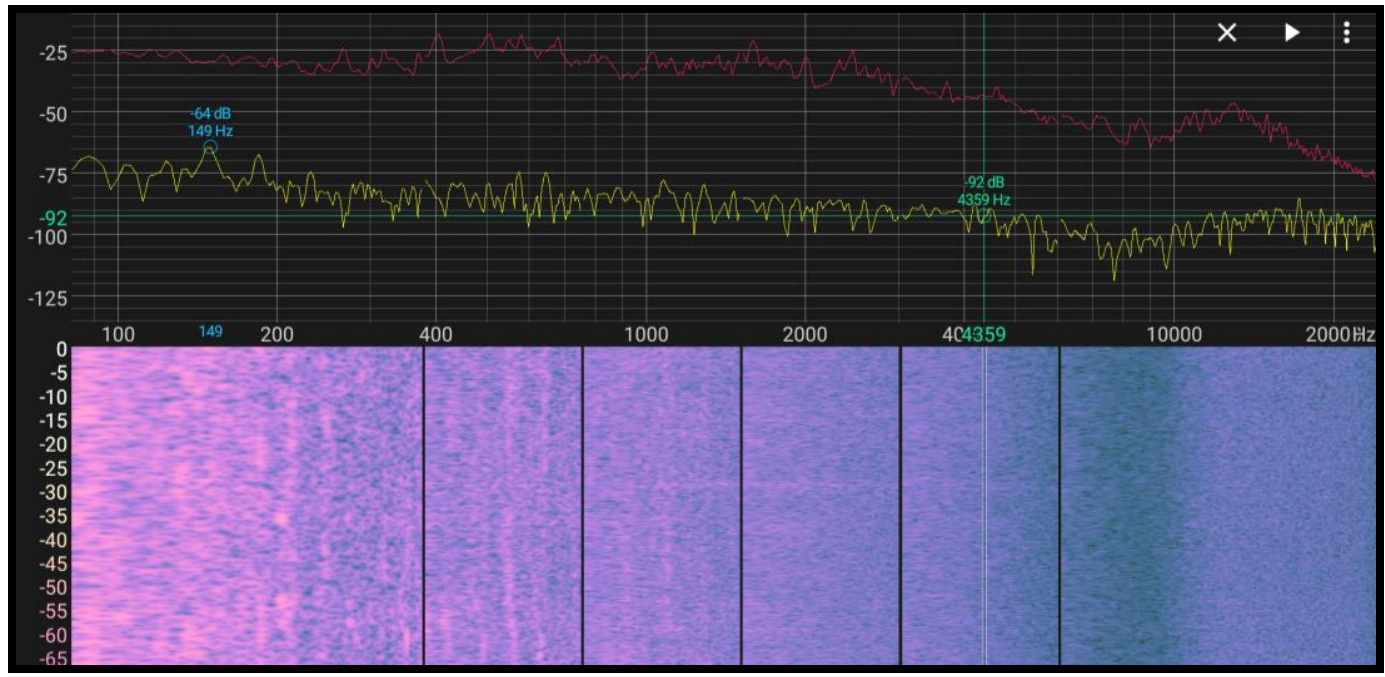

Plots were generated for each aircraft, at each altitude in an attempt to visualize the comparison between aircraft. The results are shown in Figure 6 for all aircraft at an altitude of $20 \mathrm{~m}$. Based on the findings from Phase-1, the Mavic 2 Zoom, Mavic Pro, Anafi, and PowerEgg were selected for testing during Phase- 2.

\section{Figure 6}

Plot of Aircraft SPL Versus Horizontal Distance at 20 m Altitude by Aircraft Type

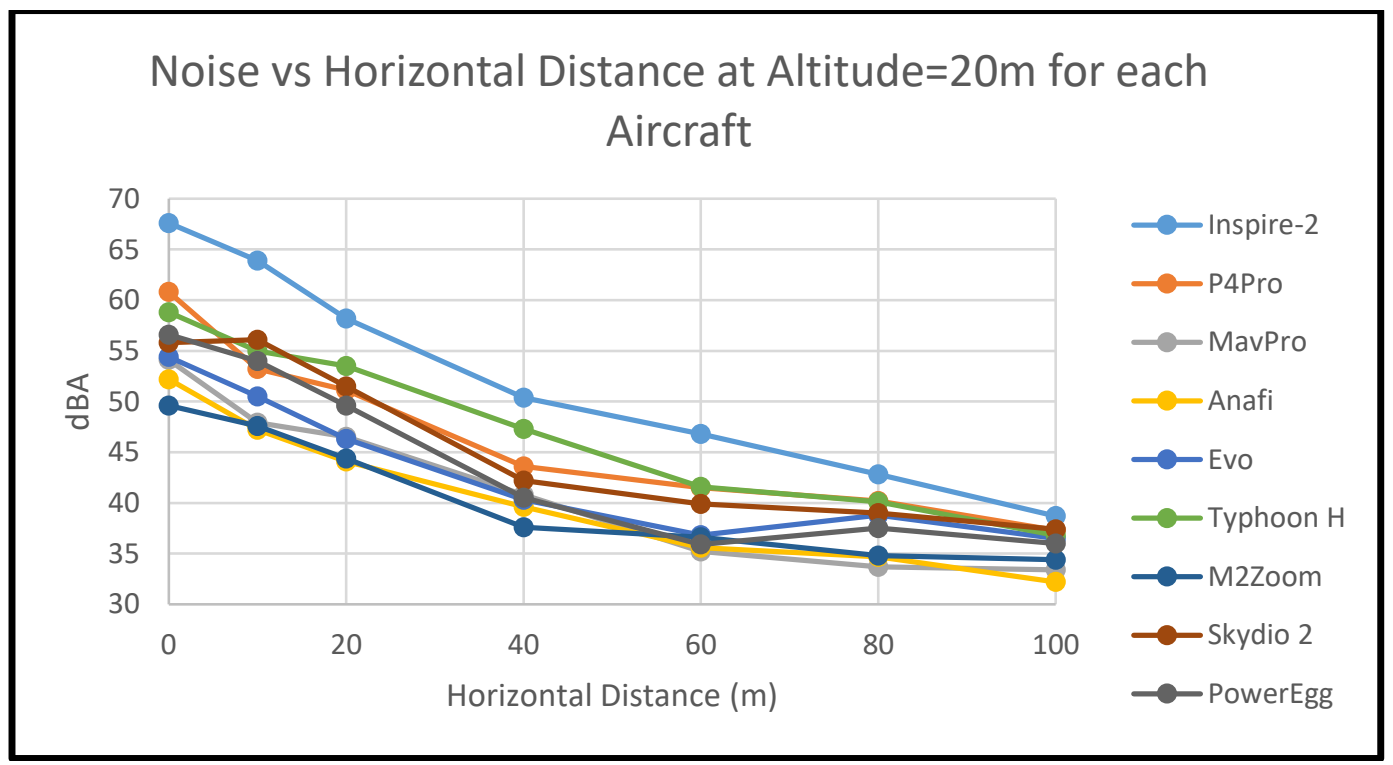




\section{Phase 2: Aircraft Acoustic Characteristics in Coastal Field Environment}

The coastal field tests were conducted on the four aircraft with the lowest acoustic signature throughout the tested flight envelope during Phase-1. This included the Mavic Pro, Mavic 2 Zoom, Anafi, and PowerEgg. The location on the Pacific Ocean provided a coastal area similar to where pinnipeds commonly gather. The topography offered waves (estimated between $0.5-1.0 \mathrm{~m}$ ) breaking on a sandy beach and large rocks. There was a light onshore breeze measured between $0.0-$ 2.2 meters per second.

The ambient ocean noise in the $20-8,000 \mathrm{~Hz}$ bandwidth varied between 59.0 and $63.3 \mathrm{dBA}$ with a mean of $62.5 \mathrm{dBA}$. The maximum aircraft noise previously recorded during the controlled field test (Phase-1) occurred with the aircraft directly overhead at an altitude of $10 \mathrm{~m}$. Of the four aircraft tested in Phase-2, all were below the ambient noise by 4.4 to $9.4 \mathrm{dBA}$ when $10 \mathrm{~m}$ directly overhead. As expected, there was no significant difference in the R8080 measured noise of any aircraft in the coastal environment since the highest SPL was environment related. There were similar results with the spectrum analyzer with only a slight indication of aircraftcreated noise in the waterfall history as seen in Figure 7. The noise pressure peaked in the $200-800 \mathrm{~Hz}$ range as shown by the light coloring (i.e., the ambient noise). The ocean noise clearly obscured recordings of the aircraft with only faint vertical waterfall history lines in the $200-600 \mathrm{~Hz}$ range and slight accompanying harmonics visible between 1000-2000 Hz. Since the aircraft noise was below the ambient levels and not detectable by the instrumentation, the Phase- 2 measurement was subjective and based on the researcher's judgement and human hearing.

Figure 7

Spectrum Trace of Mavic 2 Zoom Directly Overhead at $10 \mathrm{~m}$

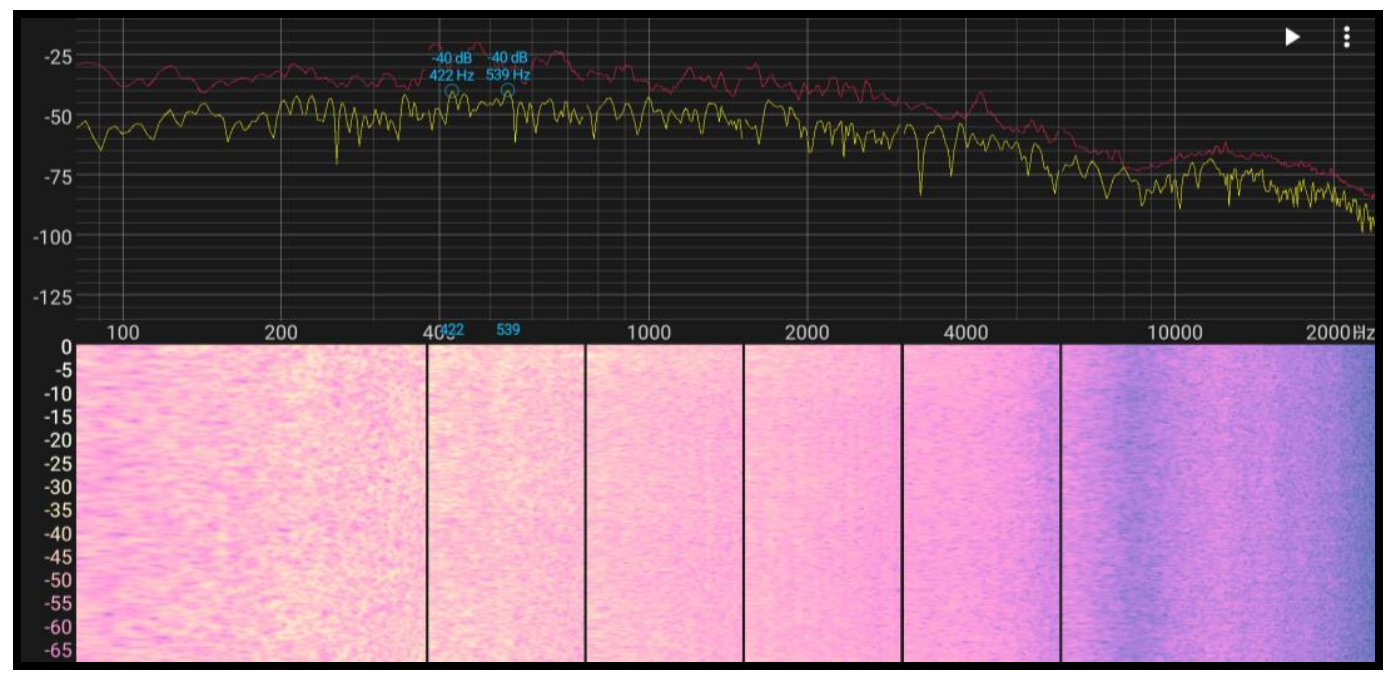


In all cases, the four aircraft were not continuously detectable by the researchers at ranges of $60 \mathrm{~m}$ and beyond. The aircraft with the lowest subjective noise footprints were the Mavic 2 Zoom and Anafi (both with the same scores). Both aircraft became intermittent at a horizontal range of $20 \mathrm{~m}$ and not detectable at $40 \mathrm{~m}$ and beyond. The subjective ratings for an altitude of $20 \mathrm{~m}$ are displayed in Figure 8.

\section{Figure 8}

Noise Level Subjective Ratings in the Coastal Environment

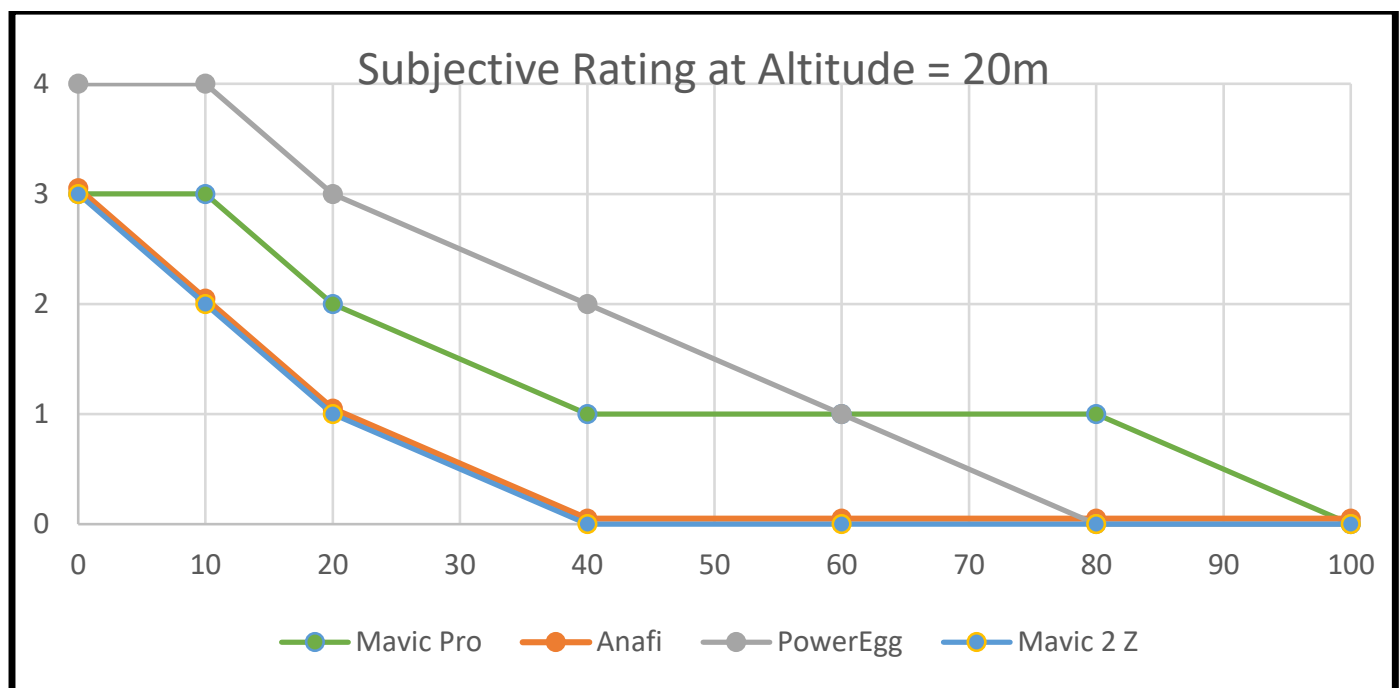

Note. No scores of " 5 " were recorded and therefore not included in this figure.

\section{Discussion}

The results highlight several areas for discussion. During the analysis of Phase-1, several regressions were attempted in order to determine whether aircraft noise could be reasonably predicted. The effect of the vertical angle from the rotor disk was analyzed to determine if angle was a significant influence on noise. Phase2 allowed generalization of how aircraft-generated noise was obscured by the natural coastal environment.

Phase 1: Aircraft Acoustic Characteristics in a Controlled Field Environment. Regression models were generated using various independent variable combinations to find the best predictor variable(s) yielding the highest prediction. Analysis indicated that the best model fit was with a single independent variable, total distance (i.e., the hypotenuse of the altitude-distance triangle). In all cases, logarithmic regression of the total distance yielded the most accurate prediction of any model. Figure 9 is a plot of the mean data points for the Typhoon $\mathrm{H}$ and the 
associated logarithmic regression equation. The total distance and noise level showed a strong, logarithmic correlation, $r(33)=.94, p<.001$ as evident in Table 1. The other aircraft exhibited similar results albeit with lower $R^{2}$ and all with a significant logarithmic relationship as summarized in Table 2.

\section{Figure 9}

Plot of Sound Level Versus Total Distance for the Typhoon H and the Associated Logarithmic Regression Curve

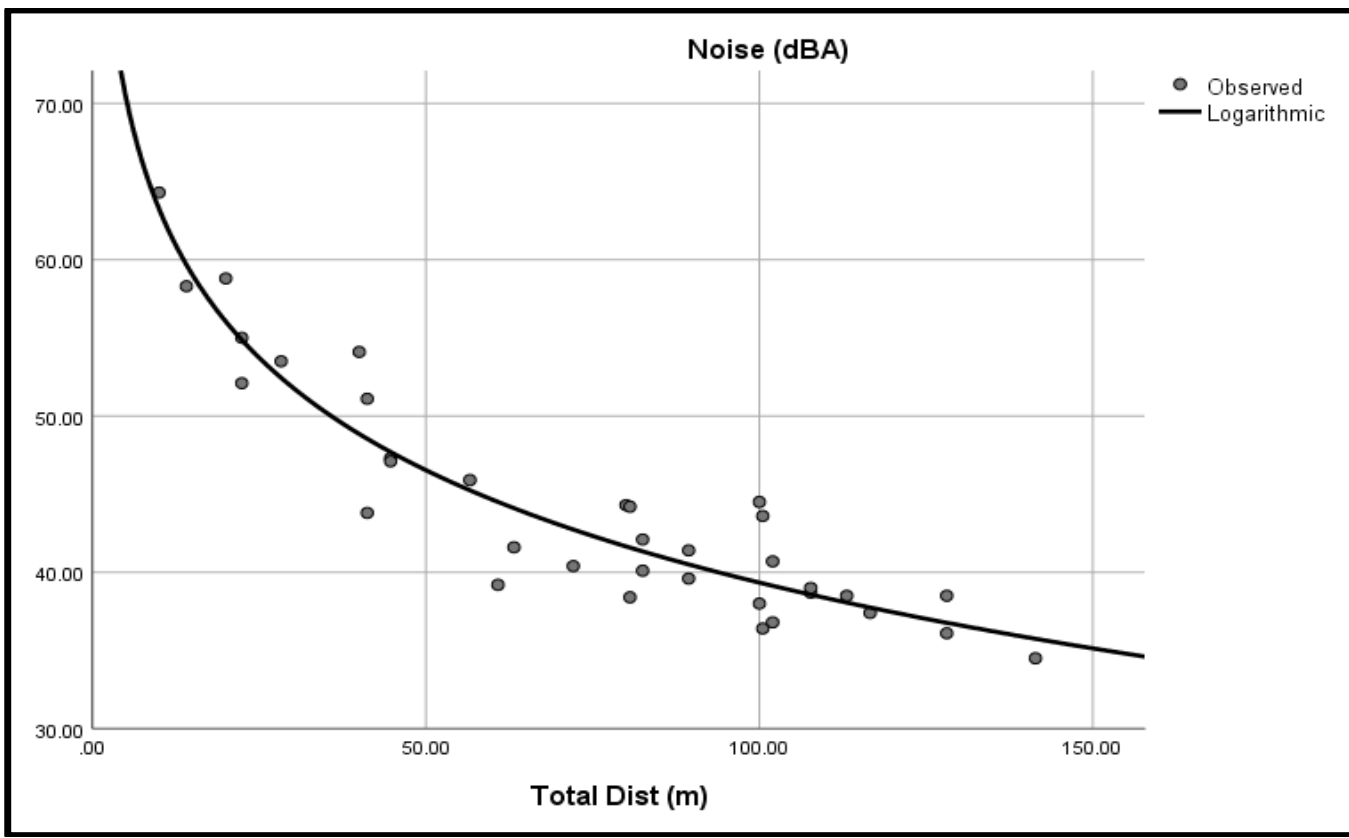

Table 1

Logarithmic Regression Model for the Typhoon $H$

\begin{tabular}{|c|c|c|c|c|c|c|c|}
\hline \multirow[b]{2}{*}{ Equation } & \multicolumn{5}{|c|}{ Model Summary } & \multicolumn{2}{|c|}{ Parameter Estimates } \\
\hline & $\begin{array}{l}\mathrm{R} \\
\text { Square }\end{array}$ & $\mathrm{F}$ & df1 & df2 & Sig. & $\begin{array}{l}\text { Constan } \\
\mathrm{t}\end{array}$ & b1 \\
\hline Logarithmic & .886 & 256.866 & 1 & 33 & .000 & 87.134 & $\begin{array}{l}- \\
10.378\end{array}$ \\
\hline
\end{tabular}


Table 2

Logarithmic Regression Results by Aircraft and Associated Values

\begin{tabular}{l|l|l|l|l} 
Aircraft & Equation & R Square & F & Sig \\
\hline Inspire-2 & Logarithmic & .712 & 81.761 & $<.001$ \\
Phantom 4 Pro & Logarithmic & .867 & 215.975 & $<.001$ \\
Mavic Pro & Logarithmic & .776 & 108.018 & $<.001$ \\
Anafi & Logarithmic & .751 & 99.723 & $<.001$ \\
Evo & Logarithmic & .663 & 64.826 & $<.001$ \\
Typhoon H & Logarithmic & .886 & 256.866 & $<.001$ \\
Mavic 2 Zoom & Logarithmic & .798 & 130.552 & $<.001$ \\
SkyDio 2 & Logarithmic & .829 & 159.682 & $<.001$ \\
PowerEgg X & Logarithmic & .690 & 73.425 & $<.001$ \\
\hline
\end{tabular}

Further analysis of the model yielded interesting results in reference to the vertical angle. When the angles were displayed along with the regression equations in Figure 9, it was observed that the regression followed closely with the measurements at a 45 degree angle. However, results for angles less than 45 degrees were overestimated while the predictions for angles greater than 45 degrees were underestimated. Referring to Figure 9, the majority of the data above the logarithmic regression line were from angles greater than 45 degrees while the data below the line are from angles less than 45 degrees.

Previous research found an increase in noise levels near the 45-degree angle from the rotor disk to the observation point (Kloet et al., 2017). While this is generally consistent with the current study, the data further indicates that there is a general increase in noise as the angle increases. This may be due to the field environment of the study where, at lower angles, there was more ground interference (e.g., trees, terrain, rocks) working to scatter/absorb the sound propagation. Several model corrections were applied that included angle, some of which yielded a more accurate prediction of noise than the logarithmic regression alone.

\section{Phase 2: Aircraft Acoustic Characteristics in Coastal Field Environment}

During Phase- 2 testing, it became clear that the aircraft could still be heard when the aircraft noise was below the ambient SPL. The unique noise characteristics created by the motors and blades as well as the spatial release from masking (Holt \& Schusterman, 2006) allow the aircraft to be identified in the lower frequencies while fading at the higher harmonics. The environmental noise, although at a higher level than the aircraft, did not obscure the drone noise until there was a large difference between the two levels.

The subjective ratings from Phase- 2 were used to determine how the ambient noise obscured the aircraft noise. Since the aircraft generated sound pressure at various altitudes and distances were measured in Phase-1, it was 
possible to calculate how far below the ambient noise each aircraft was operating at a specific position during Phase-2, as depicted in Figure 10. Since the aircraft noise can be predicted, calculating the difference between the ambient noise and predicted aircraft noise allowed a comparison to the researcher's subjective values during Phase-2.

Figure 10

Predicted Aircraft Noise Level Below Ambient Noise

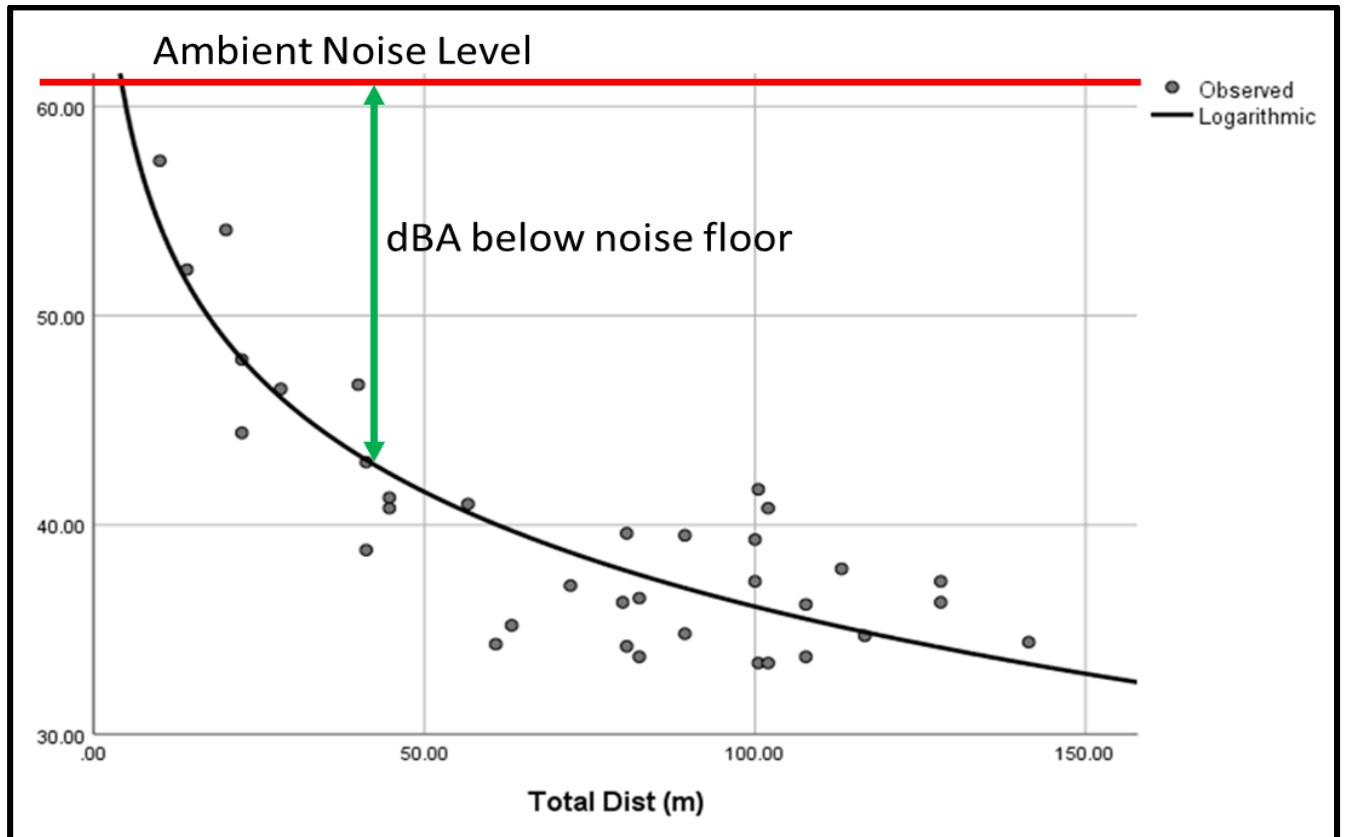

Comparing the controlled field test SPL (Phase-1) to the subjective coastal data (Phase-2) indicates that the aircraft were detectable by human hearing even when the aircraft noise was $15 \mathrm{dBA}$ less than the ambient noise (i.e., Delta $=-15$ $\mathrm{dBA}$ ), although only slightly and not by all observers. Additionally, the data shows that only predicted SPL 20dBA below the ambient noise resulted in a score of zero. Although this data is subjective and speculatory, it indicates that the coastal environment can completely mask aircraft noise to human hearing. The subjective ratings and the predicted decibel level below the ambient noise were found to be strongly correlated, $r(140)=.873, p<.001$. The boxplots of the subjective ratings as a function of the value below the ambient noise are illustrated in Figure 11. 
Figure 11

Boxplot of the Subjective Ratings as a Function of the Predicted $d B A$ Below the Ambient Noise

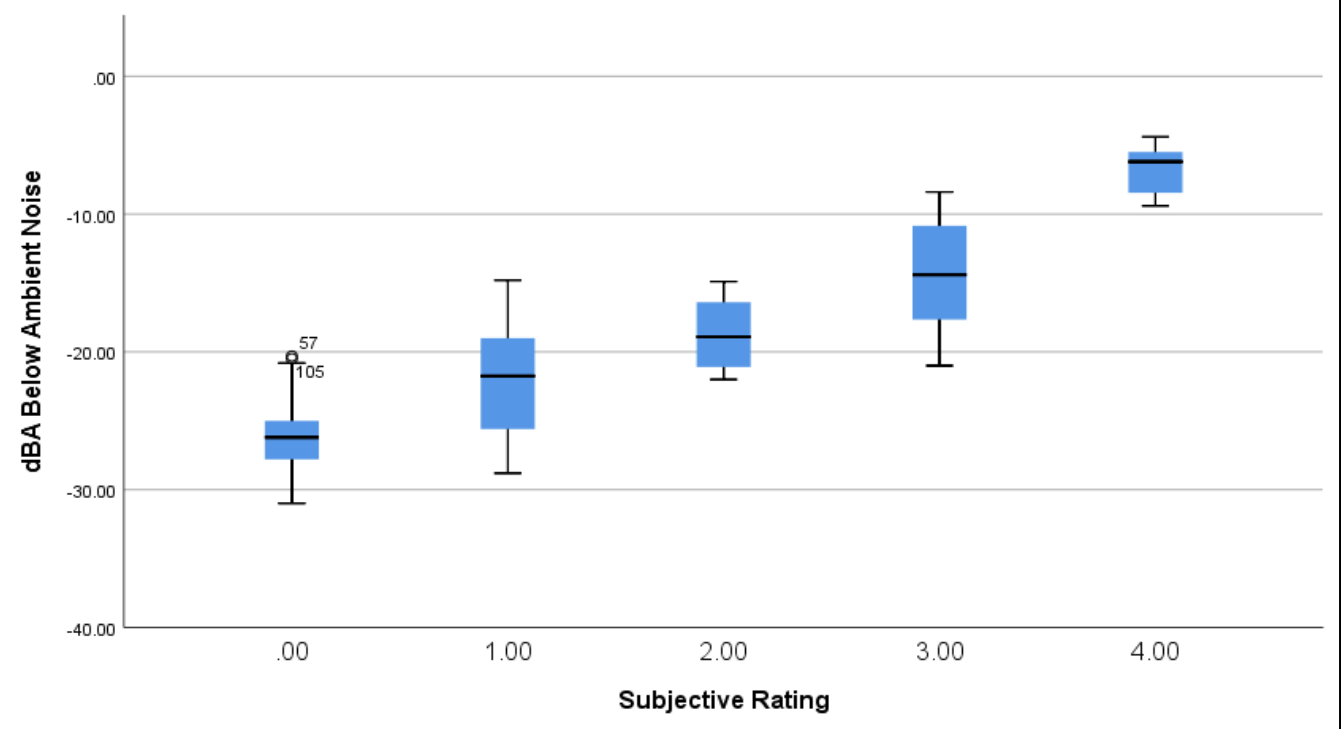

Note. No subjective ratings of 5 were observed in Phase-2; based on human hearing response.

There are some interesting connotations with these results. These data indicate that a score of "0" (i.e., aircraft cannot be heard at all) only occurred when the measured aircraft noise was at least $20 \mathrm{dBA}$ below the ambient noise. The means of both category 0 and 1 occurred when the aircraft noise is $26.1 \mathrm{dBA}$ and 22.2 dBA below the ambient noise, respectively. Further, the mean score of 3 and 4 occurred when the SPL delta was $15 \mathrm{dBA}$ or greater. The subjective ratings in this research are based on human hearing. However, these results, when considered with findings of other studies (Holt \& Schusterman 2006; Southall et al., 2003), could be used to create an envelope for aircraft operation based on pinniped's ability to distinguish acoustic signals in a noisy marine environment.

The data from Phase- 1 can now be combined with Phase- 2 to develop an operational envelope. For example, should the ability to distinguish acoustic signals in a noisy environment of particular wildlife be known, then an acceptable operating region could be calculated given the ambient SPL. This envelope is based on the difference between the ambient noise and the predicted aircraft noise. For the Mavic Pro flying in a very quiet environment ( $35 \mathrm{dBA}$ ) an example envelope is displayed in Figure 12. For the same aircraft in an environment similar to that tested during Phase-2 (62.5 dBA), the envelope is expanded as illustrated in Figure 13. 
The data inside of each cell represents aircraft noise level in dBA (re $20 \mu \mathrm{Pa}$ ) above $(+)$ or below (-) the ambient SPL.

\section{Figure 12}

Calculated Envelope for Mavic Pro with 35 dBA Ambient Noise

\begin{tabular}{|c|c|c|c|c|c|c|c|c|c|c|c|c|c|}
\hline & 120 & 3.4 & 2.8 & 2.3 & 1.7 & 1.1 & 0.5 & -0.1 & -0.7 & -1.4 & -1.9 & -2.5 & -3.1 \\
\hline \multirow{12}{*}{ 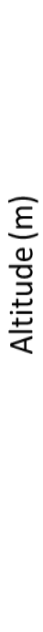 } & 110 & 4.0 & 3.4 & 2.8 & 2.2 & 1.5 & 0.8 & 0.2 & -0.5 & -1.2 & -1.8 & -2.4 & -3.0 \\
\hline & 100 & 4.7 & 4.1 & 3.4 & 2.7 & 1.9 & 1.2 & 0.4 & -0.3 & -1.0 & -1.6 & -2.3 & -2.9 \\
\hline & 90 & 5.5 & 4.8 & 4.0 & 3.2 & 2.3 & 1.5 & 0.7 & -0.1 & -0.8 & -1.5 & -2.2 & -2.9 \\
\hline & 80 & 6.3 & 5.5 & 4.6 & 3.7 & 2.8 & 1.9 & 1.0 & 0.1 & -0.7 & -1.5 & -2.2 & -2.9 \\
\hline & 70 & 7.3 & 6.3 & 5.3 & 4.2 & 3.2 & 2.1 & 1.2 & 0.3 & -0.6 & -1.4 & -2.2 & -2.9 \\
\hline & 60 & 8.3 & 7.2 & 6.0 & 4.7 & 3.5 & 2.4 & 1.3 & 0.3 & -0.6 & -1.4 & -2.2 & -2.9 \\
\hline & 50 & 9.6 & 8.1 & 6.7 & 5.2 & 3.8 & 2.6 & 1.4 & 0.3 & -0.6 & -1.5 & -2.3 & -3.1 \\
\hline & 40 & 11.0 & 9.2 & 7.3 & 5.6 & 4.0 & 2.6 & 1.4 & 0.3 & -0.7 & -1.6 & -2.5 & -3.2 \\
\hline & 30 & 12.7 & 10.2 & 7.9 & 5.8 & 4.1 & 2.5 & 1.2 & 0.1 & -1.0 & -1.9 & -2.7 & -3.5 \\
\hline & 20 & 14.7 & 11.1 & 8.1 & 5.7 & 3.8 & 2.2 & 0.9 & -0.3 & -1.3 & -2.2 & -3.0 & -3.8 \\
\hline & 10 & 16.6 & 11.2 & 7.7 & 5.2 & 3.3 & 1.7 & 0.4 & -0.7 & -1.7 & -2.6 & -3.4 & -4.1 \\
\hline & & 10 & 20 & 30 & 40 & 50 & 60 & 70 & 80 & 90 & 100 & 110 & 120 \\
\hline & & & & & $\mathrm{Ho}$ & izor & al Dis & $\operatorname{stan} c$ & $\mathrm{e}(\mathrm{m})$ & & & & \\
\hline
\end{tabular}

Note. Color coding for illustration purposes only.

\section{Figure 13}

Calculated Envelope for Mavic Pro in 62.5 dBA Ambient Noise Environment

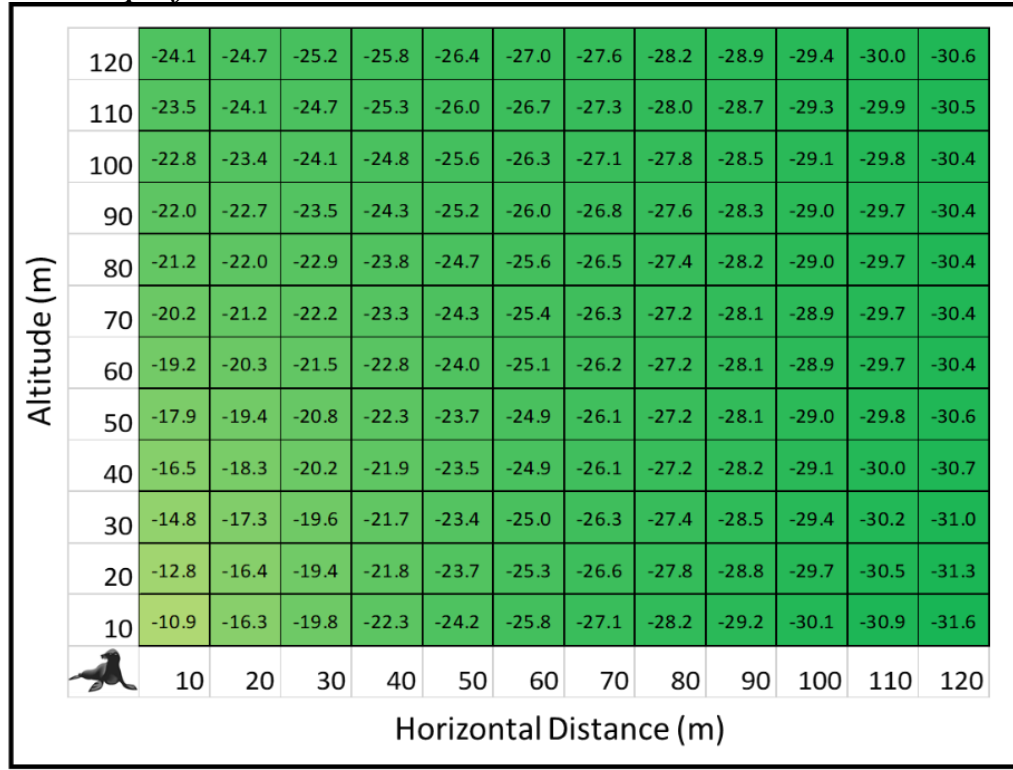

Note. Color coding for illustration purposes only. 
These envelopes (i.e., color coding) are for example purposes only. However, if the wildlife hearing response is known, it could be applied to yield an acceptable envelope. In this example, fully green is set to a -20 dBA difference between the aircraft and ambient SPL, yellow set to $-2 \mathrm{dBA}$, and fully red at +10 $\mathrm{dBA}$ and above. However, it is important to note that these envelopes only consider a single sensing point. While these envelopes may be appropriate for a single isolated individual, they may not apply to areas with pinniped aggregates or groups of wildlife, except for the vertical component.

Two other variables were not fully explored. The wind during the collection periods was light and variable and was not considered to influence the results. However, during the pilot study, winds up to $7 \mathrm{~m} / \mathrm{s}$ were experienced and anecdotally appeared to influence the noise propagation; particularly decreasing the SPL when the aircraft is downwind of the sensor. If possible, an approach to wildlife should take the wind into consideration. Making an approach from downwind of the wildlife will ensure the lowest noise possible. Also, aircraft movement was restricted during these tests and limited to hovering only.

Aircraft maneuvers change the acoustic footprint of any sUAS. Abrupt, rapid control inputs should be avoided since they will cause more aggressive braking actions by the aircraft causing higher SPLs. If operationally feasible, aircraft maneuvering while near wildlife should be in a slow, non-abrupt fashion. Some aircraft allow adjustable settings (e.g., video or sport) and even adjustment of braking intensity, which should be adjusted to minimize rapid maneuvers as described in Raoult et al. (2020).

Further research is necessary to determine at which level specific wildlife negatively respond to the aircraft noise. With this information, acoustic safety envelopes can be developed taking the hearing response of the specific wildlife into account. Additionally, the transmitted drone noise below the water's surface should be studied. While this research measured SPL in an open-air environment, the level of sound pressure transitioning into a seawater medium may vary drastically and should be studies; especially for wildlife habitats that exist near the water's surface. While light does not penetrate water as fast as in air, acoustic pressure is transmitted approximately five-times faster in seawater depending on temperature, salinity, and depth.

\section{Conclusion}

Nine sUAS were tested in Phase-1 and the four producing the lowest overall SPLs were flown in Phase-2: DJI Mavic Pro, DJI Mavic-2 Zoom/Pro/Enterprise Dual, Parrot Anafi, and PowerVision PowerEgg X. The drones developing the lowest SPLs were the Mavic 2 Zoom/Pro/Enterprise Dual equipped with aftermarket propellers, and the Parrot Anafi with OEM propellers. In all cases, the aircraft generated SPL was strongly logarithmically correlated to the total slantrange distance. Using the logarithmic regression, the SPL for the tested drones was 
predicted and can be used to determine an acceptable envelope to be based for the specific wildlife being monitored.

The sUAS noise was detectable even when operating well below the ambient noise level. The unique noise and harmonics created by the drone allowed detection based on sound characteristics not native to the marine environment. During Phase-2, the tested aircraft became intermittently detected or not detected at all when the predicted SPL was $23.0 \mathrm{dBA}$ or more below the ambient coastal noise level (62.5 dBA). 


\section{References}

Aniceto, A. S., Biuw, M., Lindstrøm, U., Solbø, S. A., Broms, F., \& Carroll, J. (2018). Monitoring marine mammals using unmanned aerial vehicles: Quantifying detection certainty. Ecosphere, 9(3). https://doi.org/10.1002/ecs2.2122

Adame, K., Pardo, M. A., Salvadeo, C., Beier, E., \& Elorriaga-Verplancken, F. R. 2017. Detectability and categorization of California sea lions using an unmanned aerial vehicle. Marine Mammal Science, 33, 913-925.

Feight, J. A., Whyte, S., Jacob, J. D., \& Gaeta, R. J. (2017). Acoustic characterization of a multi-rotor UAS as a first step towards noise reduction. https://doi.org/10.2514/6.2017-1174

Fiori, L., Doshi, A., Martinez, E., Orams, M. B., \& Bollard-Breen, B. (2017). The use of unmanned aerial systems in marine mammal research. Remote Sensing (Basel, Switzerland), 9(6), 543. https://doi.org/10.3390/rs9060543

Fust, P., \& Loos, J. (2020). Development perspectives for the application of autonomous, unmanned aerial systems (UASs) in wildlife conservation. Biological Conservation, 241, 108380. https://doi.org/10.1016/j.biocon.2019.108380

Goebel, M. E., Perryman, W. L., Hinke, J. T., Krause, D. J., Hann, N. A., Gardner, S., \& LeRoi, D. J. (2015). A small unmanned aerial system for estimating abundance and size of Antarctic predators. Polar Biology, 38(5), 619-630. https://doi.org/10.1007/s00300-014-1625-4

Holt, M. M., \& Schusterman, R. J. (2006). Spatial release from masking of aerial tones in pinnipeds. Acoustical Society of America, 121(2), 1219-1225. https://doi.org/10.1121/1.2404929

Islam, R., Stimpson, A., \& Cummings, M. (2017). Small UAV noise analysis. Humans and autonomy laboratory. https://hal.pratt.duke.edu/ sites/hal.pratt.duke.edu/files/u24/Small_UAV_Noise_Analysis_rqi.pdf

Kloet, N., Watkins, S., \& Clothier, R. (2017). Acoustic signature measurement of small multi-rotor unmanned aircraft systems. International Journal of Micro Air Vehicles, 9(1), 3-14. https://doi.org/10.1177/1756829316681868

Krause, D. J., Hinke, J. T., Perryman, W. L., Goebel, M. E., \& LeRoi, D. J. (2017). An accurate and adaptable photogrammetric approach for estimating the mass and body condition of pinnipeds using an unmanned aerial system. PloS One, 12(11), e0187465-e0187465. https://doi.org/10.1371/journal.pone.0187465

Malchaire, J. (2001). Sound measuring instruments. Occupational exposure to noise: Evaluation, prevention and control. Federal Institute for Occupational Safety and Health, Dortmund 125-140. 
Marine Mammal Commission (2016). Development and use of UASs by the national marine fisheries service for surveying marine mammals. Marine Mammal Commission. Retrieved from https://www.mmc.gov/.

McIntosh, R. R., Holmberg, R., \& Dann, P. (2018). Looking without landingusing remote piloted aircraft to monitor fur seal populations without disturbance. Frontiers in Marine Science, 5. https://doi.org/10.3389/ fmars.2018.00202

NOAA's National Marine Fisheries Service Marine Mammal Commission (2018). Marine mammal protection act. Retrieved from https://www.fisheries.noaa.gov/national /marine-mammalprotection/marine-mammal-protection-act\#download-the-full-pdf-version

Palomino-González, A, Kovacs, K. M, Lydersen, C., Ims, R. A, \& Lowther, A. D. (2021). Drones and marine mammals in Svalbard, Norway. Mar Mam Sci. 1- 18. https://doi.org/10.1111/mms.12802

Raoult, V., Colefax, A. P., Allan, B. M., Cagnazzi, D., Castelblanco-Martínez, N., Ierodiaconou, D., Johnston, D. W., Landeo-Yauri, S., Lyons, M., Pirotta, V., Schofield, G., \& Butcher, P. A. (2020). Operational protocols for the use of drones in marine animal research. Drones (Basel), 4(64), 64. https://doi.org/10.3390/drones4040064.

Ruser, A., Daehne, M., Sundermeyer, J., Lucke, K., Houser, D. S., Finneran, J. J. \& Siebert, U. (2014). In-air evoked potential audiometry of grey seals (halichoerus grypus) from the north and Baltic seas. PloS One, 9(3). doi:10.1371/journal.pone.0090824

Seymour, A. C., Dale, J., Hammill, M., Halpin, P. N., \& Johnston, D. W. (2017). Automated detection and enumeration of marine wildlife using unmanned aircraft systems (UAS) and thermal imagery. Scientific Reports, 7(1), https://doi.org/10.1038/srep45127

Schofield, G., Esteban, N., Katselidis, K. A., \& Hays, G. C. (2019). Drones for research on sea turtles and other marine vertebrates $-\mathrm{A}$ review. Biological Conservation, 238. https://doi.org/10.1016/j.biocon.2019.108214

Smith, C. E., Sykora-Bodie, S. T., Bloodworth, B., Pack, S. M., Spradlin, T. R., \& LeBoeuf, N. R. (2016). Assessment of known impacts of unmanned aerial systems (UAS) on marine mammals: Data gaps and recommendations for researchers in the United States. Journal of Unmanned Vehicle Systems, 4(1), 31-44. https://doi.org/10.1139/juvs-2015-0017

Sorrell, K. J., Clarke, R. H., Holmberg, R., \& McIntosh, R. R. (2019). Remotely piloted aircraft improve precision of capture-mark-resight population estimates of Australian fur seals. Ecosphere (Washington, DC), 10(8), n/a. https://doi.org/10.1002/ecs2.2812

Southall, B. L., Schusterman, R. J., \& Kastak, D. (2003). Auditory masking in three pinnipeds: Aerial critical ratios and direct critical bandwidth 
measurements. The Journal of the Acoustical Society of America, 114(3), 1660-1666. doi:10.1121/1.1587733 